\title{
Efficacy and Safety of Supplemental Transarterial Chemoembolization Through Extrahepatic Collateral Arteries with Drug-eluting Beads: Treatment for Unresectable Hepatocellular Carcinoma
}

This article was published in the following Dove Press journal: Drug Design, Development and Therapy

\author{
Sung-Hua Chiu' \\ Ping-Ying Chang ${ }^{2}$ \\ Yu-Lueng $\mathrm{Shih}^{3}$ \\ Wen-Yen Huang ${ }^{4}$ \\ Kai-Hsiung Ko' \\ Wei-Chou Chang' \\ Guo-Shu Huang' \\ 'Department of Radiology, Tri-Service \\ General Hospital, National Defense \\ Medical Center, Taipei, Taiwan; ${ }^{2}$ Division \\ of Hematology/Oncology, Department of \\ Internal Medicine, Tri-Service General \\ Hospital, National Defense Medical \\ Center, Taipei, Taiwan; ${ }^{3}$ Division of \\ Gastroenterology, Department of \\ Internal Medicine, Tri-Service General \\ Hospital, National Defense Medical \\ Center, Taipei, Taiwan; ${ }^{4}$ Department of \\ Radiotherapy, Tri-Service General \\ Hospital, National Defense Medical \\ Center, Taipei, Taiwan
}

Correspondence: Wei-Chou Chang Department of Radiology, Tri-Service General Hospital, National Defense Medical Center, Taipei, Taiwan

Tel +886-2-8792-33I I ext. \#I6480

Fax +886-2-8792-7245

Email Weichou.chang@gmail.com
Purpose: To evaluate the therapeutic efficacy and safety of supplement transarterial chemoembolization (TACE) with drug-eluting beads TACE (DEB-TACE) through extrahepatic collateral (EHC) arteries for the treatment of hepatocellular carcinoma (HCC).

Patients and Methods: In this retrospective study, 61 unresectable HCC patients with treatment-naïve EHC blood supplies who received TACE from January 2016 to March 2019 were enrolled; of these patients, 42 (68.9\%) received DEB-TACE, and 19 (31.1\%) received cTACE. The hepatic tumor feeding arteries were treated in the same TACE session if it presented. The tumor response, time-to-progression (TTP), and overall survival (OS) were analyzed. Safety was assessed based on the occurrence of liver function deterioration and major complications within three months after TACE.

Results: DEB-TACE showed better efficacy than cTACE in the disease control rate ( $p=0.001)$, overall response rate $(p=0.005)$, the TTP (eight months vsthree months, $p=0.002)$ and the OS (23.8 months vs nine months, $p=0.045)$. Nine patients in the DEBTACE group and one patient in the cTACE group were downstaged to resection or liver transplantation $(21.4 \%$ vs $5.3 \%, p=0.151)$. DEB-TACE and cTACE have no difference in the acute and chronic liver toxicity. With regard to complications, there was no significant difference in the occurrence of both major $(16.7 \%$ vs $21.1 \%, p=0.72)$ and minor $(57.1 \%$ vs $47.4 \%, p=0.48$ ) complications between DEB-TACE and cTACE.

Conclusion: DEB-TACE through EHC arteries has a potential therapeutic effect in the treatment of unresectable HCC, with comparable safety compared with cTACE.

Keywords: hepatocellular carcinoma, chemoembolization, therapeutic, collateral circulation, cone-beam computed tomography

\section{Plain Language Summary}

As a widely-selected and mature treatment of unresectable hepatocellular carcinoma (HCC), transarterial chemoembolization (TACE) has been developed for decades and is considered as first-line therapy to intermediate-stage HCC patients. There are two types of TACEconventional TACE (cTACE) and drug-eluting beads TACE (DEB-TACE). cTACE has been applied in the treatment of HCC for more than three decades, and DEB-TACE emerged in recent years as a more standardized drug-delivering technique which can achieve higher 
doses of chemotherapeutic agent and prolonged contact time with cancer cells. Moreover, DEB-TACE is considered as more tolerable treatment than cTACE.

Interventional radiologists found (attributed to the development of radiological technology) that extrahepatic collateral (EHC) arteries will supply HCC in addition to hepatic arteries, which may make treatment of HCC incomplete and even fail. Thus, TACE through these EHC arteries has been evaluated in many studies and showed its therapeutic efficacy. Currently, the studies focusing on TACE through EHC arteries are limited to cTACE, and our study is the first one to evaluate the therapeutic efficacy and safety of DEB-TACE through EHC arteries. Our results showed that DEB-TACE through EHC arteries has a potential therapeutic effect in the treatment of unresectable HCC, with comparable safety compared with cTACE, which means that DEB-TACE may become another option for patients with unresectable HCC.

\section{Introduction}

Hepatocellular carcinoma (HCC) is the most common primary liver malignancy in adults that strongly associated with cirrhosis, from both alcohol and viral etiologies. HCC typically receives blood supplies from branches of the hepatic artery, accounting for its characteristic image appearance: strong arterial enhancement with early "washout" pattern. In unresectable HCC, transarterial chemoembolization (TACE) is the most widely-selected treatment, and is considered as first-line therapy in BCLC-B (intermediate stage) patients. ${ }^{1}$ TACE can improve survival of HCC patients, on the basis of the HCC supplying arteries could be embolized to produce ischemic necrosis. Moreover, in the recent studies, 2,3 TACE showed survival benefit in BCLC-C (advanced stage) patients when combined with target therapy.

The conventional TACE (cTACE) has been applied in the treatment of $\mathrm{HCC}$ for more than 30 years, ${ }^{4,5}$ which works by delivering chemoagent into hepatic tumors with emulsion of Lipiodol ${ }^{\circledR}$ (Iodinated ethyl esters of fatty acids of poppyseed oil). Though cTACE is a mature and widely-accepted treatment for unresectable $\mathrm{HCC}$, it has some drawbacks, including low local concentration of chemoagent within tumor and complications caused by systemic circulation of chemoagent. ${ }^{6}$

Drug-eluting beads (DEBs), also called drug-eluting microspheres (DEMs), have been introduced into the transarterial treatment of HCC since the 2000s, ${ }^{7}$ which can load chemoagents through ion exchange and absorption $^{7-9}$ and release chemoagents in a sustained manner. This pharmacokinetic property of DEBs can lead to higher intratumoral chemoagent concentration, and in the same time lower systemic circulation of chemoagents. ${ }^{7}$ Although DEB-TACE does not have significant superiority in terms of therapeutic efficacy and safety than cTACE to date, this new method is considered more tolerable to patients because of lower systemic toxicity. ${ }^{10}$

Most of the time, HCC is supplied by hepatic arteries; however, when the tumor becomes more advanced, it has exophytic growth, locates adjacent to the bare area of liver, and has been previously treated, ${ }^{11}$ it may recruit extrahepatic arteries for its vascular supply. The estimated prevalence of extrahepatic collateral (EHC) blood supplies ranges from 17$27 \%{ }^{11}$ Presence of EHC blood supplies to HCC may hinder the optimal response of TACE, causing treatment failure.

With the development of interventional radiology, more EHC blood supplies of HCC were identified before and during TACE, which prompts discussion about the efficacy and safety of TACE of EHC arteries. cTACE is applied in clinical practice with a longer period than DEBTACE, thus articles focusing on the TACE of EHC blood supplies are limited to cTACE. ${ }^{12-15}$ In the other words, the role of DEB-TACE in the treatment of EHC blood supplies of HCC is still undetermined.

To the best of our knowledge, this study is the first one that focus on the therapeutic efficacy and safety of DEBTACE through EHC arteries, which may become another therapeutic option for patients with unresectable HCC.

\section{Methods \\ Study Design}

This was a retrospective single-center study that evaluated the therapeutic efficacy and safety of DEBTACE in the treatment of EHC blood supplies of unresectable HCC. The study followed the protocol and principles of the Declaration of Helsinki, was in accordance with the International Conference on Harmonization Tripartite Guideline for Good Clinical Practice. Institutional Review Board (IRB) approval was obtained by Tri-Service General Hospital (1-105-05-158) with a waiver of informed consent because the waiver or alteration will not adversely affect the rights and welfare of the subjects, and all patient data were protected under the rules of IRB. All patients were evaluated by a multidisciplinary tumor board, which was composed of all of the medical specialists involved in managing the HCC patients (hepatologist, oncologist, hepatic and transplant surgeon, radiotherapist, radiologist and interventional radiologist). The inclusion criteria were as follows: (a) HCC 
diagnosed by pathology or by noninvasive methods criteria according to the American Association for the Study of Liver Diseases (AASLD) guidelines $;{ }^{16}$ (b) acceptable performance status (PS 0-1); (c) HCCs confirmed to be supplied by EHC arteries during angiography by either DSA or $\mathrm{CBCT}$, and EHC feeding arteries was not previously embolized; (d) normal liver or compensated cirrhosis with preserved liver function (Child-Pugh score A or B); and (e) adequate renal function (serum creatinine $<1.5$ times the upper limit of normal).

The exclusion criteria were as follows: (a) platelet count $<40,000 / \mu \mathrm{L}$ and/or international normalized ratio $>1.5$; (b) contraindications to arterial endovascular procedures; (c) contraindications to doxorubicin; (d) patients with Vp4 portal vein thrombosis according to the Liver Cancer Study Group of Japan classification; ${ }^{17}$ and (e) extrahepatic metastases.

\section{Patient Evaluations}

The computerized search of database for HCC patients from January 2016 to March 2019 was performed for retrospective chart and image review. There were 575 unresectable HCC patients received TACE in our intervention department. Of these patients, 61 ( $n=42$ with DEB-TACE; $n=19$ with cTACE) with identifiable EHC blood supplies and embolized during TACE were recruited (Figure 1).

The median follow-up time was 12 months (range: $0.5-46.3)$.

\section{DSA and CBCT Performance}

The procedure was conducted using an Axiom Artis (Siemens Healthcare AG, Forchheim, Germany) device. DSA was performed during TACE to map the vessels and detect hypervascular tumor stains. Diagnostic visceral angiography of the celiac trunk and superior mesenteric artery was first performed to identify the arterial supply to the liver and determine the patency of the portal vein. After installing CBCT in our institution in 2018, we also performed $\mathrm{CBCT}$ during hepatic arteriography (CBCT$\mathrm{HA}$ ), in addition to DSA, to confirm the feeding territories of the branches of hepatic arteries. If DSA and CBCT-HA of all possible branches of hepatic arteries showed no or incomplete tumor stain, then the potential EHC arteries would be catheterized. After catheterizing the EHC arteries, both DSA and CBCT during arteriography was performed to determine feeding territories and identify tumor-feeding arteries. TACE was performed after confirming the tumor-feeding arteries. If angiographically apparent arterioportal or arteriovenous shunt was identified, we would manage it based on its timing of opacification. ${ }^{18}$ In shunts with slow ( $>3$ seconds) and intermediate (1.5-3 seconds) flow, we embolized the shunt with gelfoam before TACE. In shunts with high (0.5-1.5 seconds) flow, this TACE would be suspended. After TACE, NE-CBCT was performed to visually estimate the degree of marginal contrast material saturation of

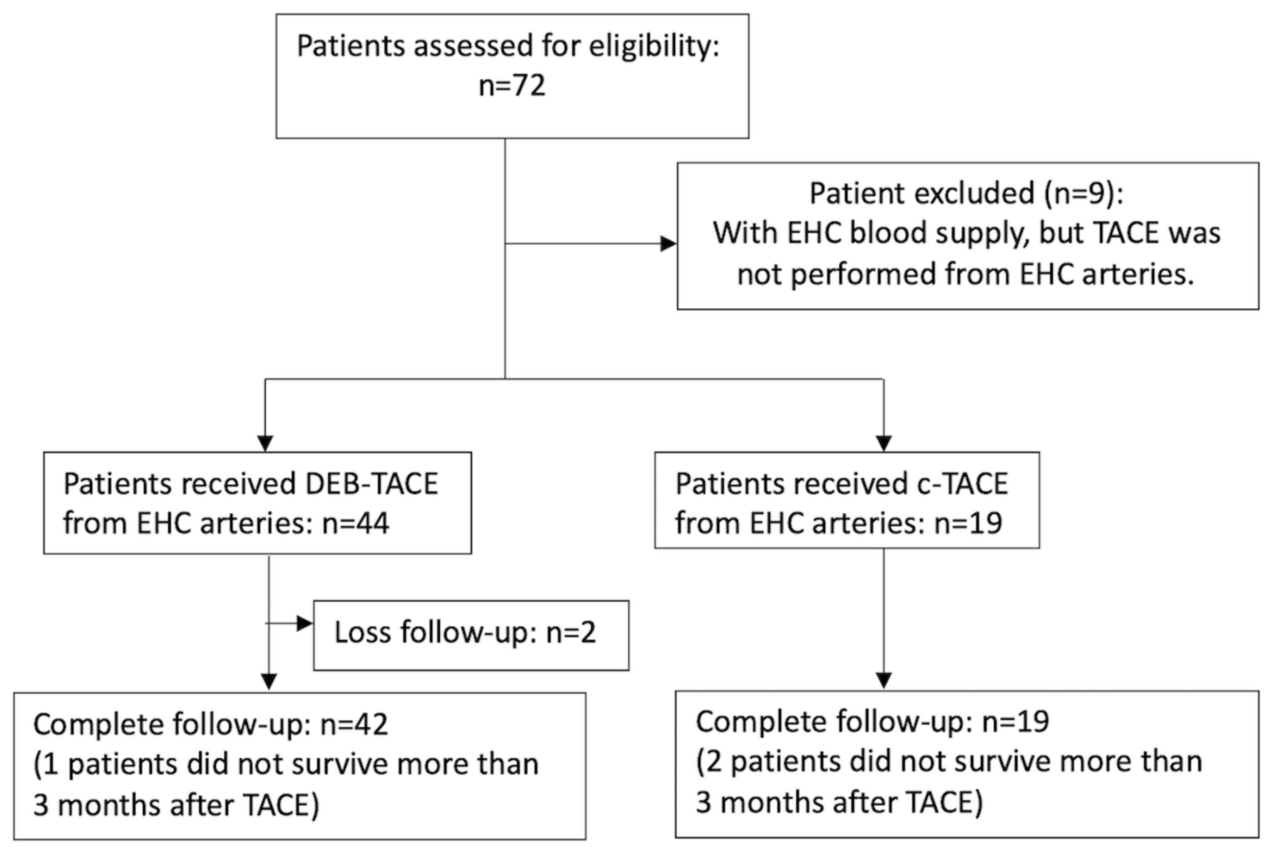

Figure I Flow chart representing the inclusion of the patients. 
the entire tumor volume ${ }^{19}$ and detect potential nontarget embolization.

\section{Treatment}

For DEB-TACE, we used 30-60 $\mu \mathrm{m}$ HepaSpheres (Merit Medical, South Jordan, Utah, USA), and each vial of HepaSpheres $(25 \mathrm{mg})$ was mixed with $50 \mathrm{mg}$ doxorubicin (solubilized in $\mathrm{NaCl} 0.9 \%$ solution) one hour before the procedure to maximize the uptake of the chemoagents into the spheres. With its swelling behavior, after loading, HepaSphere microsphere would become $120-240 \mu \mathrm{m}$ in size. Then, the loaded HepaSpheres were mixed with $20 \mathrm{~mL}$ nonionic contrast to form a homogeneous suspension. The maximum dose administered was $100 \mathrm{mg}$ doxorubicin (loaded with two vials of HepaSpheres). For cTACE, Lipiodol ${ }^{\circledR}$ (Guerbet, France) was used as the carrier of doxorubicin, and the maximum dose administered was $100 \mathrm{mg}$ doxorubicin. Gelfoam sponges were also used as adjuvant embolizing agents. Based on the policy of our institution, we did not perform both DEBTACE and cTACE in the same TACE session. If hepatic tumor feeding arteries were identified, concurrent TACE through the hepatic arteries was also performed in the same TACE session. The endpoint of TACE was to achieve reduced residual antegrade arterial flow and reduced even nonresidual tumor brush, which was classified as level II-III in subjective angiographic chemoembolization endpoint scale. ${ }^{20}$ For DEB-TACE, if the endpoint was not achieved after administration of HepaSpheres, gelfoam sponges would be used for decreasing blood flow.

\section{Clinical and Radiological Follow-Up}

Treatment response was evaluated by multidetector row computed tomography (MDCT) or magnetic resonance imaging (MRI) as overall (per-patient) response based on the modified Response Evaluation Criteria in Solid Tumors (mRECIST) ${ }^{21}$ three months after each TACE session. Time-to-progression (TTP) refers to the time between the performance of TACE sessions and the time of disease progression. The patients who successfully underwent resection or liver transplantation after TACE were documented as downstaged. Overall survival (OS) was defined as the time from the performance of TACE sessions to death or the date of the last follow-up for patients who were alive and censored.

\section{Safety}

Liver toxicity was defined as worsening results according to the Common Terminology Criteria for Adverse Events
(CTCAE, v 5.0) compared with the baseline levels before TACE for any of the following parameters: aspartate aminotransferase (AST), alanine aminotransferase (ALT), and total bilirubin. Liver function was examined $48 \mathrm{~h}$ (defined as short-term) and one month (defined as long-term) after TACE session to evaluate liver toxicity. The number of postTACE major and minor complications that occurred within three months after treatment was documented. Major complication was defined as an event that leads to substantial morbidity and disability, an increased level of care, or substantially lengthens hospital stay. ${ }^{22}$

\section{Statistical Analysis}

Quantitative variables were expressed as the median, mean and range, and categorical variables were expressed as the count and proportion. The differences between subgroups were evaluated by chi-squared tests or Fisher's exact tests for categorical variables and by Student's $t$-tests for quantitative variables. TTP and OS curves were created using the Kaplan-Meier method and compared using Breslow (generalized Wilcoxon) tests. A conventional $p$-value $<0.05$ was considered significant. The last date for data collection was January 31, 2020. All calculations were performed with SPSS version 26 (IBM Corporation, Armonk, NY, USA).

\section{Results}

\section{Baseline Characteristics of the Patients}

As shown in Table 1, 57.4\% of the patients were hepatitis $\mathrm{B}$ virus carriers, and $23.0 \%$ were hepatitis $\mathrm{C}$ virus carriers. In total, $85.2 \%$ of the patients were asymptomatic (performance status 0 ) and the remaining were performance status 1 . Before the TACE procedure, only $16.4 \%$ of the patients were considered Child-Pugh B (remaining were Child-Pugh A), and only two patients (3.3\%) had an albumin-bilirubin (ALBI) grade $>2$. There were 12 patients with BCLC stage $\mathrm{C}$ disease, of whom five did not receive target therapy after TACE because of contraindications to sorafenib.

\section{Baseline Imaging Characteristics, Angiographic and $\mathrm{CBCT}$ Findings}

Among the 61 patients, $54.1 \%$ of patients had a single $\mathrm{HCC}$ (Table 2), and mean tumor number was 2.4 (range: 1-9). Seventy-two percent of patients had HCCs located in the single lobe, and the remaining had bilobar HCCs. In total, 71 HCCs were supplied by EHC arteries, and six of them were supplied by two EHC arteries (Table 3). The mean target tumor size was $4.84 \mathrm{~cm}$, and 29 of them (40.8\%) were naïve 
Table I Baseline Patient Characteristics of HCC Patients with EHC Blood Supplies

\begin{tabular}{|c|c|c|c|c|}
\hline Patient Characteristics & All & DEB-TACE & cTACE & $p$-value \\
\hline Number & 61 & 42 & 19 & \\
\hline $\begin{array}{l}\text { Gender } \\
\text { Male } \\
\text { Female }\end{array}$ & $\begin{array}{l}50(82.0 \%) \\
\text { II (I8.0\%) }\end{array}$ & $\begin{array}{l}32(76.2 \%) \\
10(23.8 \%)\end{array}$ & $\begin{array}{l}\text { I8 (94.7\%) } \\
\text { I (5.3\%) }\end{array}$ & 0.077 \\
\hline $\begin{array}{l}\text { Causes of HCC } \\
\text { HBV } \\
\mathrm{HCV} \\
\mathrm{HBV}+\mathrm{HCV} \\
\text { Others }\end{array}$ & $\begin{array}{l}35(57.4 \%) \\
14(23.0 \%) \\
4(6.6 \%) \\
8(13.0 \%)\end{array}$ & $\begin{array}{l}26(61.9 \%) \\
7(16.7 \%) \\
3(7.1 \%) \\
6(14.3 \%)\end{array}$ & $\begin{array}{l}9(47.4 \%) \\
7(36.8 \%) \\
1(5.3 \%) \\
2(10.5 \%)\end{array}$ & 0.413 \\
\hline Median age (years) & $\begin{array}{l}65.0 \\
(27.0-87.6)\end{array}$ & $\begin{array}{l}63.7 \\
(27.0-86.0)\end{array}$ & $\begin{array}{l}67.4 \\
(41.0-87.6)\end{array}$ & 0.289 \\
\hline $\begin{array}{l}\text { Child-Pugh class } \\
\text { A } \\
\text { B }\end{array}$ & $\begin{array}{l}51(83.6 \%) \\
10(16.4 \%)\end{array}$ & $\begin{array}{l}34(81.0 \%) \\
8(19.0 \%)\end{array}$ & $\begin{array}{l}17(89.5 \%) \\
2(10.5 \%)\end{array}$ & 0.485 \\
\hline $\begin{array}{l}\text { BCLC stage } \\
\text { A } \\
\text { B } \\
\text { C }\end{array}$ & $\begin{array}{l}33(54.1 \%) \\
16(26.2 \%) \\
12(19.7 \%)\end{array}$ & $\begin{array}{l}20(47.6 \%) \\
14(33.3 \%) \\
8(19.1 \%)\end{array}$ & $\begin{array}{l}13(68.4 \%) \\
2(10.5 \%) \\
4(21.1 \%)\end{array}$ & 0.160 \\
\hline $\begin{array}{l}\text { ECOG performance } \\
\qquad \begin{array}{l}1 \\
1\end{array}\end{array}$ & $\begin{array}{l}44(72.1 \%) \\
17(27.9 \%)\end{array}$ & $\begin{array}{l}32(71.4 \%) \\
10(28.6 \%)\end{array}$ & $\begin{array}{l}12(68.4 \%) \\
7(31.6 \%)\end{array}$ & 0.121 \\
\hline $\begin{array}{l}\text { AFP level, median } \\
(\mathrm{ng} / \mathrm{mL})\end{array}$ & $\begin{array}{l}9.7 \\
(1.0-19210.5)\end{array}$ & $\begin{array}{l}10.9 \\
(1.0-4599.8)\end{array}$ & $\begin{array}{l}7.7 \\
(1.5-19210.5)\end{array}$ & 0.107 \\
\hline $\begin{array}{l}\text { Albumin/bilirubin } \\
\text { (ALBI) grade } \\
\text { Grade I } \\
\text { Grade } 2 \\
\text { Grade } 3\end{array}$ & $\begin{array}{l}15(24.6 \%) \\
44(72.1 \%) \\
2(3.3 \% 0\end{array}$ & $\begin{array}{l}10(23.8 \%) \\
31 \text { ( } 73.8 \%) \\
\text { I (2.4\%) }\end{array}$ & $\begin{array}{l}5(26.3 \%) \\
13(68.4 \%) \\
I(5.3 \%)\end{array}$ & 0.812 \\
\hline $\begin{array}{l}\text { Target therapy after } \\
\text { TACE }\end{array}$ & 7 (11.5\%) & 5 (11.9\%) & $2(10.5 \%)$ & 0.292 \\
\hline $\begin{array}{l}\text { Mean number of } \\
\text { prior TACE }\end{array}$ & $\begin{array}{l}1.16 \pm 1.12 \\
(0-4)\end{array}$ & $\begin{array}{l}I .7 I \pm 1.1 \mid \\
(0-4)\end{array}$ & $\begin{array}{l}1.53 \pm 1.17 \\
(0-4)\end{array}$ & 0.550 \\
\hline
\end{tabular}

Abbreviations: AFP, alpha-fetoprotein; BCLC, Barcelona Clinic Liver Cancer; CTACE, conventional transarterial chemoembolization; DEB-TACE, drugeluting beads transarterial chemoembolization; ECOG, Eastern Cooperative Oncology Group; EHC, extrahepatic collateral; HBV, hepatitis B virus; HCC, hepatocellular carcinoma; HCV, hepatitis C virus; TACE, transarterial chemoembolization.

lesions. Twenty-three patients in the DEB-TACE group and nine patients in the cTACE group also received concurrent chemoembolization of the hepatic tumor-feeding arteries in the same TACE session ( $54.8 \%$ vs $47.4 \%, p=0.592)$. The anatomical location of the tumors and their EHC supplying arteries are summarized in Table 4. The inferior phrenic artery (IPA) was the most common EHC artery (Figures 2 and 3), with more than a $75 \%$ prevalence in every area of the liver except segments five and six, where the lumbar arteries were the most common (37.5\%) source of EHC blood supplies to HCCs. In total, $54.7 \%$ of the HCCs with EHC blood supplies were located in segment seven and the bare area of the liver.

\section{Treatment Response, Downstaging, TTP, and OS}

As shown in Figure 4, the disease control rate at three months after TACE was $81.0 \%$ in the DEB-TACE group and $36.8 \%$ in the cTACE group ( $p=0.001)$, and the overall 
Table 2 Baseline Imaging Characteristics of HCC Before TACE

\begin{tabular}{|c|c|c|c|c|}
\hline Imaging Characteristics & $\begin{array}{l}\text { All TACE } \\
(n=6 I)\end{array}$ & $\begin{array}{l}\text { DEB-TACE } \\
(n=42)\end{array}$ & $\begin{array}{l}\text { cTACE } \\
(n=19)\end{array}$ & $p$-value \\
\hline Number of target lesions ${ }^{\mathrm{a}}$ & 71 & 49 & 22 & \\
\hline $\begin{array}{l}\text { Received prior treatment } \\
\text { Naïve } \\
\text { Non-naïve }\end{array}$ & $\begin{array}{l}29(40.8 \%) \\
42(59.2 \%)\end{array}$ & $\begin{array}{l}19(38.8 \%) \\
30(61.2 \%)\end{array}$ & $\begin{array}{l}10(45.5 \%) \\
12(54.5 \%)\end{array}$ & 0.392 \\
\hline $\begin{array}{l}\text { Tumor burden } \\
\text { Single } \\
\text { Multifocal } \\
\text { Infiltrating }\end{array}$ & $\begin{array}{l}33(54.1 \%) \\
26(42.6 \%) \\
2(3.3 \%)\end{array}$ & $\begin{array}{l}21(50.0 \%) \\
20(47.6 \%) \\
I(2.4 \%)\end{array}$ & $\begin{array}{l}12(63.2 \%) \\
6(31.6 \%) \\
1(5.3 \%)\end{array}$ & 0.463 \\
\hline $\begin{array}{l}\text { Tumor location } \\
\text { Unilobar } \\
\text { Bilobar }\end{array}$ & $\begin{array}{l}44(72.1 \%) \\
17(27.9 \%)\end{array}$ & $\begin{array}{l}29(69.0 \%) \\
13(31.0 \%)\end{array}$ & $\begin{array}{l}15 \text { (78.9\%) } \\
4 \text { (2I.1\%) }\end{array}$ & 0.544 \\
\hline Tumor number & $2.4 \pm 2.1$ & $2.2 \pm 1.8$ & $2.7 \pm 2.7$ & 0.465 \\
\hline Mean target lesions size $(\mathrm{cm})$ & $4.84 \pm 4.30$ & $4.83 \pm 4.55$ & $4.87 \pm 3.76$ & 0.970 \\
\hline $\begin{array}{l}\text { Macroscopic PVTT } \\
\text { None } \\
V_{p 2} \\
V_{p} 3\end{array}$ & $\begin{array}{l}49(80.3 \%) \\
4(6.6 \%) \\
8(13.1 \%)\end{array}$ & $\begin{array}{l}34(81.0 \%) \\
2(4.8 \%) \\
6(14.2 \%)\end{array}$ & $\begin{array}{l}15(79.0 \%) \\
2(10.5 \%) \\
2(10.5 \%)\end{array}$ & 0.921 \\
\hline
\end{tabular}

Note: ${ }^{\text {TT }}$ The preTACE imaging characteristics of target lesions were confirmed retrospectively based on DSA or CBCT findings during TACE.

Abbreviations: cTACE, conventional transarterial chemoembolization; DEB-TACE, drug-eluting beads transarterial chemoembolization; HCC, hepatocellular carcinoma; PVTT, portal vein tumor thrombosis; TACE, transarterial chemoembolization.

response rate was also significantly higher in the DEBTACE group $(59.5 \%)$ than in the cTACE group $(21.1 \%)$ $(p=0.005)$. The median TTP was eight months (range: 1.0-32.7) in the DEB-TACE group and three months in the cTACE group (median range: 0.5-42.5), which was a significant difference ( $p=0.001$ ) (as shown in Figure 5A). Nine patients in the DEB-TACE group and one patient in the cTACE group were downstaged to resection or liver transplantation $(21.4 \%$ vs $5.3 \%, p=0.151)$. The median OS in the DEB-TACE group was 23.8 months (range: 1.8-$46.3)$, which was significantly longer $(p=0.045)$ than the nine months (range: 0.5-44.0) in the cTACE group (as shown in Figure 5B).

\section{Liver Toxicity and Incidence of Both Major and Minor Complications}

As shown in Table 5, patients who received concurrent chemoembolization of the hepatic tumor-feeding and EHC arteries in the same TACE session had significantly more short-term (48 h) increases in AST and ALT levels than those who received chemoembolization of only the EHC arteries $(p<0.001)$. This difference was not identified one month (long-term) after TACE, and no grade 3-4 liver toxicity was documented in any of the patients. There was no difference in the short-term and long-term liver toxicities between the DEB-TACE and cTACE groups.

The type and frequency of complications that occurred within three months after TACE were demonstrated in Figure 6, and there was no significant difference in the occurrence of both major $(16.7 \%$ vs $21.1 \%, p=0.72)$ and minor $(57.1 \%$ vs $47.4 \%, p=0.48)$ complications between DEB-TACE and cTACE.

\section{Discussion}

Recent developments in the field of interventional radiology have led to a renewed interest in EHC blood supplies to HCC. To the best of our knowledge, our study is the first one to evaluate the therapeutic efficacy and safety of DEB-TACE through EHC arteries for the treatment of unresectable HCC. In this study, DEB-TACE led to better tumor response and OS than cTACE with comparable safety. TACE of the EHC arteries alone did not significantly increase short-term liver toxicity, regardless of which TACE method was applied. On-site CBCT showed a tendency to lower the occurrence of major complications during the TACE through EHC arteries. 
Table 3 Angiographic Findings During TACE

\begin{tabular}{|l|l|}
\hline Parameters & Percentage \\
\hline $\begin{array}{l}\text { Number of EHC arteries supplied the HCCs } \\
\text { Only one vessel }\end{array}$ & $65(91.6 \%)$ \\
Two vessels & $6(8.4 \%)$ \\
\hline $\begin{array}{l}\text { Type of EHC arteries } \\
\text { Inferior phrenic artery }\end{array}$ & $57(80.3 \%)$ \\
$\quad$ Lumbar artery & $8(10.4 \%)$ \\
Gastroduodenal artery & $4(5.2 \%)$ \\
$\quad$ Ouperior mesentery artery & $3(3.9 \%)$ \\
\hline Coexistence of blood supply from hepatic arteries & $5(7.8 \%)$ \\
$\quad$ Yes & $32(45.1 \%)$ \\
$\quad$ No & $39(54.9 \%)$ \\
\hline $\begin{array}{l}\text { Detection of EHC blood supply on HCCs } \\
\text { I. Suspicion of EHC blood supply on HCCs before }\end{array}$ & $23(32.5 \%)$ \\
$\quad \begin{array}{l}\text { TACE } \\
\text { I. Large-size HCCs }\end{array}$ & $10(14.1 \%)$ \\
I. Suspected EHC blood supply based on CT/MRIs & $7(9.9 \%)$ \\
I. Suspected EHC blood supply by prior TACEs & $6(8.5 \%)$ \\
I. Evidence of EHC blood supply on DSA & $36(50.4 \%)$ \\
I. No or incomplete tumor stain of hepatic arteries & $22(31.4 \%)$ \\
on DSA & $12(17.1 \%)$ \\
I. Tumor stain of RIPA on DSA & $2(1.9 \%)$ \\
I. SMA shows evidence of EHC blood supply & $12(17.1 \%)$ \\
I. Evidence of EHC blood supply on additional CBCT & \\
\hline
\end{tabular}

Abbreviations: $\mathrm{CBCT}$, cone-beam computed tomography; CT, computed tomography; DSA, digital subtraction angiography; EHC, extrahepatic collateral; HCC, hepatocellular carcinoma; MRI, magnetic resonance imaging; RIPA, right inferior phrenic artery; TACE, transarterial chemoembolization; SMA, superior mesenteric artery.

To date, the comparative efficacy of DEB-TACE and cTACE remains undetermined. ${ }^{10}$ Song et $\mathrm{al}^{23}$ showed a better efficacy with DEB-TACE than with cTACE; however, the PREVISION V study ${ }^{24}$ and another retrospective $\operatorname{study}^{25}$ found no difference in the efficacy of these two types of TACE. Miyayama et $\mathrm{al}^{26}$ reported that cTACE has an advantage in treating small HCC because Lipiodol ${ }^{\circledR}$ can be retained in the tumor sinusoid and portal vein with a better blockage effect than DEBTACE, which can only embolize the arterial side of the tumor blood supply. However, with advances in minimizing the particle size of drug-eluting beads, this blockage effect may also be achieved with DEBTACE. In our study, DEB-TACE revealed better treatment response and survival benefit over cTACE. The particle (30-60 $\mu \mathrm{m}$ HepaSpheres) used in our study was smaller than that in the PREVISION V study, ${ }^{24}$ and smaller particle size can lead to more distal penetration $^{27}$ and subsequent higher survival rate. ${ }^{28}$ Drug-eluting beads can achieve higher doses of chemotherapeutic agent and prolonged contact time with cancer cells, and which could make a superiority to cTACE in terms of tumor response.

PREVISION V study ${ }^{24}$ showed a significant reduction in liver toxicity in DEB-TACE than in cTACE, but Song et $\mathrm{al}^{23}$ and Golfieri et $\mathrm{al}^{29}$ found no difference between the two types of TACE. In our study, TACE of EHC arteries alone does not significantly increase the short-term liver toxicity, regardless of which TACE method was used. Precisely, it could be implied that the most determining risk factor for liver damage is the hepatic artery chemoembolization, not the EHC arteries. Furthermore, no grade 3-4 liver toxicity was documented in all patients in our study, indicating that TACE of EHC arteries is safe with regard to liver function.

Table 4 Locations of HCCs and Percentage of EHC Arteries

\begin{tabular}{|c|c|c|c|c|c|c|c|}
\hline & $\begin{array}{l}\text { Bare } \\
\text { Area } \\
(n=26)\end{array}$ & $\begin{array}{l}\text { Segment } \\
7 \\
(n=15)\end{array}$ & $\begin{array}{l}\text { Left Lateral } \\
\text { Segment } \\
(n=9)\end{array}$ & $\begin{array}{l}\text { Exophytic } \\
\text { Growth } \\
(n=8)\end{array}$ & $\begin{array}{l}\text { Segment 5/ } \\
6 \\
(n=8)\end{array}$ & $\begin{array}{l}\text { Segment } \\
4 \\
(n=5)\end{array}$ & $\begin{array}{l}\text { Segment } \\
8 \\
(n=4)\end{array}$ \\
\hline $\begin{array}{l}\text { Inferior phrenic artery } \\
\text { Lumbar artery } \\
\text { Gastroduodenal artery } \\
\text { Superior mesentery } \\
\text { artery } \\
\text { Internal mammary } \\
\text { artery } \\
\text { Right renal artery } \\
\text { Splenic artery } \\
\text { Left adrenal artery }\end{array}$ & $\begin{array}{l}20(76.9 \%) \\
3(11.5 \%) \\
2(7.7 \%) \\
1(3.9 \%)\end{array}$ & $\begin{array}{l}12(80.0 \%) \\
2(13.3 \%) \\
\text { I (6.7\%) }\end{array}$ & $\begin{array}{l}7 \text { (77.8\%) } \\
\text { I (I I.I\%) } \\
\text { I (I I.I\%) }\end{array}$ & $\begin{array}{l}6 \text { (75.0\%) } \\
\text { I (12.5\%) } \\
\text { I }(12.5 \%)\end{array}$ & $\begin{array}{l}3(37.5 \%) \\
3(37.5 \%) \\
\text { I }(12.5 \%) \\
\text { I }(12.5 \%)\end{array}$ & I (20.0\%) & I (25.0\%) \\
\hline
\end{tabular}

Abbreviations: EHC, extrahepatic collateral; HCC, hepatocellular carcinoma. 

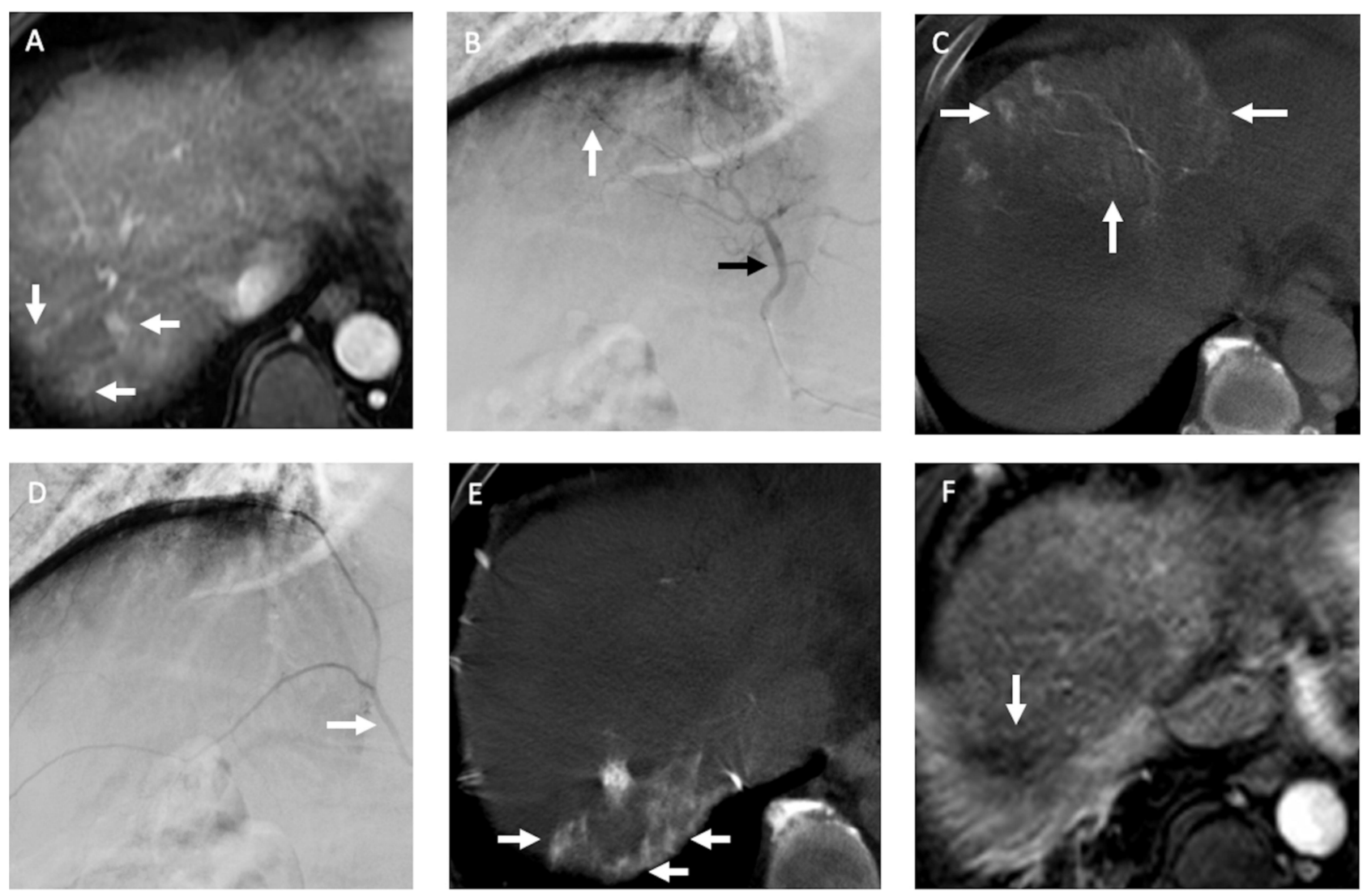

Figure 2 Recurrent HCCs in a 60-year old man with nonB and nonC cirrhosis of liver and HCC in segment seven received radiofrequency ablation (RFA) before. (A) The arterial phase of dynamic MRI study before TACE showed three small recurrent HCCs (arrows) in segment seven of the liver abutting prior RFA site. (B) During TACE, the DSA of middle hepatic artery (black arrow) demonstrated suspected hypervascular tumor stains (arrow) near liver dome. (C) However, the CBCT-HA of middle hepatic artery indicated it supplied segments four and eight of the liver (arrows), not segment seven where recurrent HCCs were located. (D) The DSA of right inferior phrenic artery (RIPA) (arrow) revealed no distinct hypervascular tumor stain. (E) The following CBCT-A of RIPA confirmed it supplied the recurrent HCCs (arrows) in segment seven of the liver, and chemoembolization with drug-eluting beads was then performed. (F) One month after TACE, the MRI study indicated complete response (arrow) of the recurrent HCCs.

The safety of transarterial management for HCC with the IPA has been evaluated in several studies, ${ }^{12-15}$ and most of the adverse events were pulmonary complications, of which fewer than $5 \%$ met the definition for major complications. ${ }^{13}$ In our study, DEB-TACE and cTACE showed no significant difference in both major and minor complications. With regard to pulmonary complications, only one $(2.4 \%)$ and two $(10.5 \%)$ patients in DEB-TACE and cTACE groups respectively met the definition of major complications. In other words, performance of TACE through EHC arteries has acceptable risk in both DEB-TACE and cTACE.

CBCT has shown its ability to improve diagnostic performance $^{30-32}$ during TACE and to predict treatment response. $^{33,34}$ In addition, the role of CBCT in the TACE of $\mathrm{EHC}$ arteries has been evaluated, ${ }^{35,36}$ which observed that $\mathrm{CBCT}$ has potential to detect EHC blood supplies and provide additional imaging information to prevent nontarget embolization. Moreover, in our study, we found that
NE-CBCT can indicate possible nontarget embolization (as shown in Figure 7) immediately after treatment in both DEB-TACE and cTACE, providing early alert of potential complications.

Our study has some limitations. First, the study was retrospective. To date, no randomized trials have been designed to evaluate the optimal frequency of therapy. TACE was usually performed by an "on demand" strategy according to tumor response as observed on imaging, not at a regular predefined time interval. Second, presence of EHC feeding arteries of HCC may not be detected in previous TACE session in our patients because of limitation in predicting the EHC blood supplies. ${ }^{11}$ Third, there was no dose-tumor response evaluation in both DEBTACE and cTACE. DEB-TACE has been increasingly used as the first-line transcatheter treatment for HCC in our clinical practice. DEB-TACE provides a standardized drug-loading process to HCC treatment offering consistency and repeatability not available with cTACE. Fourth, 

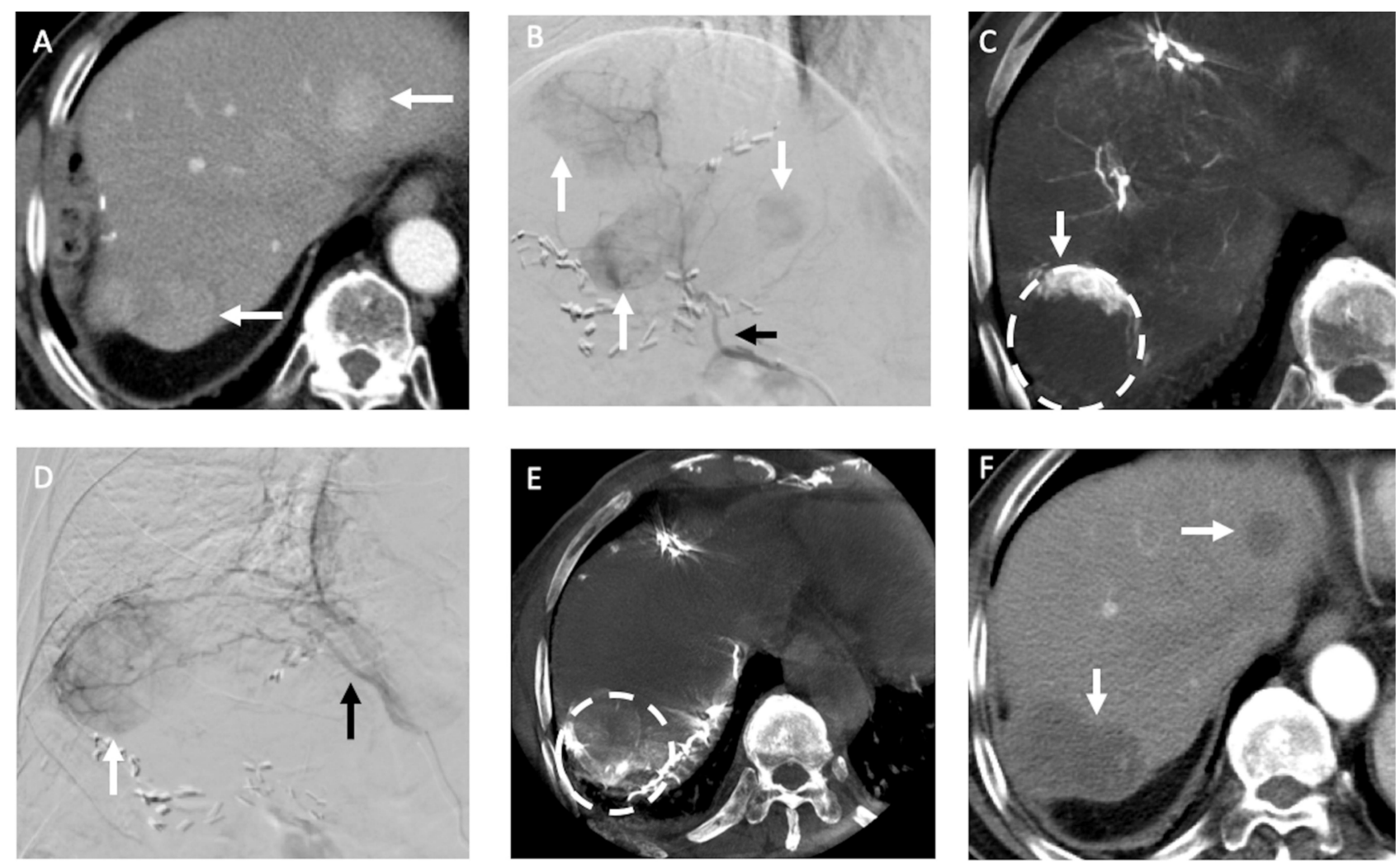

Figure 3 Recurrent HCCs in an 83-year-old man with HBV cirrhosis of liver and HCC in segment seven received hepatectomy before. (A) The arterial phase of MDCT before TACE showed two recurrent HCCs (arrows) in the both lobes of liver. (B) During TACE, the DSA of right hepatic artery (black arrow) demonstrated three hypervascular tumors (arrows) in both lobes of the liver (one was not in the same cut of MDCT). (C) The following CBCT-HA of right hepatic artery indicated the recurrent HCC in segment seven (dotted line) was only enhanced in its anterior portion (arrow); the nonenhanced portion may be supplied by other vessels. (D) The DSA of RIPA (black arrow) showed a hypervascular tumor (arrow) near liver dome. (E) The following CBCT-A of RIPA confirmed the posterior portion of recurrent HCC in segment seven (dotted line) was supplied by RIPA, and chemoembolization with drug-eluting beads was then performed. (F) One month after TACE, the MDCT indicated complete response (arrows) of the recurrent HCCs.

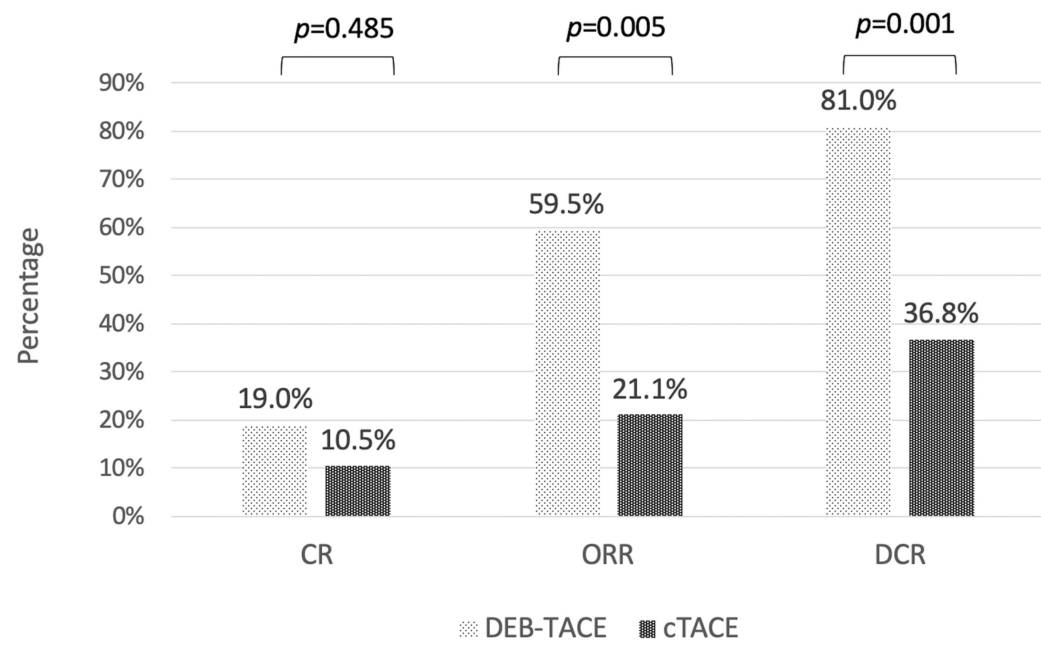

Figure 4 Treatment response three months after TACE according to mRECIST in DEB-TACE and cTACE groups. Treatment response in DEB-TACE group was significantly higher than in cTACE group in both objective response rate (ORR), complete response plus partial response, and disease control rate (DCR), ORR plus stable disease.

Notes: One patient in the DEB-TACE group and two patients in the c-TACE group did not survive for more than three months after TACE; thus, no tumor response data could be acquired.

despite seven patients in the study also receiving target therapy during their treatment course, we did not exclude them because they began their target therapy more than three months after the first TACE. Fifth, overall response assessment was used in this study to evaluate tumor response after TACE rather than target lesion assessment. 
A Kaplan-Meier Time-to-progression (TTP) estimates

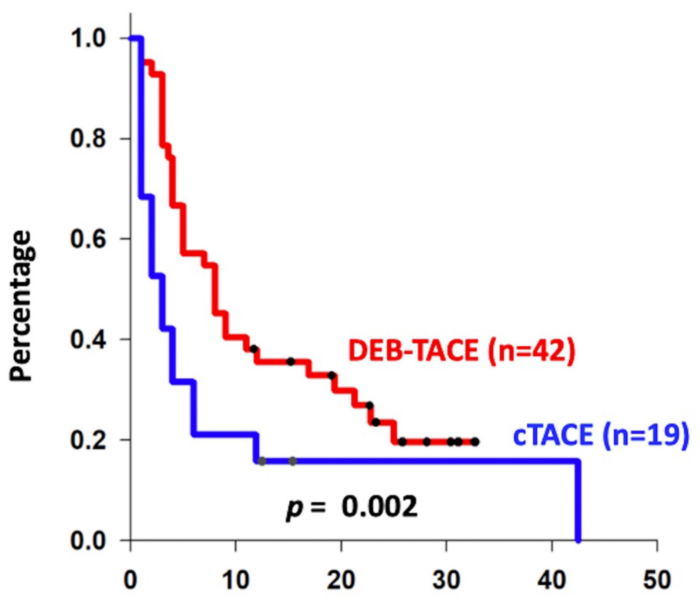

Analytic time (months)

\begin{tabular}{lccccc} 
At risk & & & & & \\
\hline DEB-TACE & 42 & 17 & 10 & 3 & 0 \\
cTACE & 19 & 4 & 1 & 1 & 1 \\
\hline
\end{tabular}

B

Kaplan-Meier Overall survival (OS) estimates

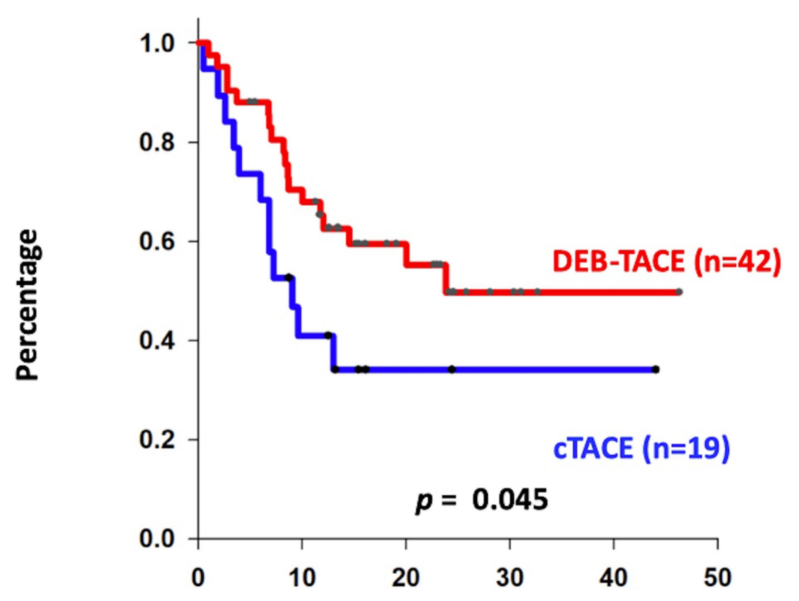

Analytic time (months)

\begin{tabular}{lrrrrr} 
At risk & & & & & \\
\hline DEB-TACE & 42 & 28 & 14 & 4 & 1 \\
cTACE & 19 & 7 & 2 & 1 & 1 \\
\hline
\end{tabular}

Figure 5 Kaplan-Meier time-to-progression curve (A) and overall survival curve $(\mathbf{B})$ according to the type of TACE.

To date, there are insufficient data to indicate that target lesions, nontarget lesions, and new lesions. In this retrolesion assessment is a reliable imaging predictor for patient outcome. In contrast, in mRECIST, overall spective study, we used overall response to represent the response is a result of the combined assessment of target treatment efficiency because $45.9 \%$ of the patients had multiple HCCs, and DEB-TACE was performed to

Table 5 Liver Toxicity 48 Hours and One Month After TACE Session

\begin{tabular}{|c|c|c|c|c|c|c|c|c|c|}
\hline & \multicolumn{3}{|c|}{ DEB-TACE } & \multicolumn{3}{|c|}{ C-TACE } & \multirow{2}{*}{$\begin{array}{l}+H A \\
(n=32)\end{array}$} & \multirow{2}{*}{$\begin{array}{l}-H A \\
(n=29)\end{array}$} & \multirow[t]{2}{*}{$p$-value } \\
\hline & $\begin{array}{l}+\mathrm{HA} \\
(n=23)\end{array}$ & $\begin{array}{l}-\mathrm{HA} \\
(n=19)\end{array}$ & $p$-value & $\begin{array}{l}+\mathrm{HA} \\
(n=9)\end{array}$ & $\begin{array}{l}-\mathrm{HA} \\
(n=10)\end{array}$ & $p$-value & & & \\
\hline \multicolumn{10}{|c|}{ Liver toxicity $48 \mathrm{~h}$ after TACE } \\
\hline $\begin{array}{l}\text { Bilirubin } \\
\text { (grade I/2) }\end{array}$ & $5 / 6$ & $5 / 4$ & 0.904 & $3 / 2$ & $3 / 3$ & 0.929 & $8 / 8$ & $8 / 7$ & 0.974 \\
\hline $\begin{array}{l}\text { AST } \\
\text { (grade } 1 / 2 / 3 / 4 \text { ) }\end{array}$ & $6 / 3 / 9 / 2$ & $5 / 2 / 1 / 0$ & 0.011 & $0 / 2 / 5 / 1$ & $3 / 0 / 0 / 0$ & 0.004 & $6 / 5 / 14 / 3$ & $8 / 2 / 1 / 0$ & $<0.001$ \\
\hline $\begin{array}{l}\text { ALT } \\
\text { (grade } 1 / 2 / 3 / 4 \text { ) }\end{array}$ & $8 / 1 / 8 / 0$ & $5 / 1 / 0 / 0$ & 0.012 & $3 / 3 / 0 / 1$ & 0/0/0/0 & 0.006 & $\mid \mathrm{I} / 4 / 8 / \mathrm{I}$ & $5 / 1 / 0 / 0$ & $<0.001$ \\
\hline \multicolumn{10}{|c|}{ Liver toxicity one month after TACE } \\
\hline $\begin{array}{l}\text { Bilirubin } \\
\text { (grade I/2) }\end{array}$ & $8 / 2$ & $5 / 2$ & 0.788 & $4 / 0$ & $\mathrm{I} / \mathrm{I}$ & 0.209 & $12 / 2$ & $6 / 3$ & 0.339 \\
\hline $\begin{array}{l}\text { AST } \\
\text { (grade } 1 / 2 / 3 / 4 \text { ) }\end{array}$ & $6 / 0 / 0 / 0$ & $5 / 1 / 0 / 0$ & 0.552 & $1 / 0 / 0 / 0$ & $2 / 0 / 0 / 0$ & 0.500 & $7 / 0 / 0 / 0$ & $7 / 1 / 0 / 0$ & 0.545 \\
\hline $\begin{array}{l}\text { ALT } \\
\text { (grade } 1 / 2 / 3 / 4 \text { ) }\end{array}$ & $4 / 0 / 0 / 0$ & $2 / 0 / 0 / 0$ & 0.668 & $0 / 0 / 0 / 0$ & $\mathrm{I} / 0 / 0 / 0$ & 0.500 & $4 / 0 / 0 / 0$ & $3 / 0 / 0 / 0$ & 1.000 \\
\hline
\end{tabular}

Abbreviations: +HA, concurrent chemoembolization of hepatic and EHC tumor feeding arteries; - HA, chemoembolization of only extrahepatic tumor feeding arteries; ALT, alanine transaminase; AST, aspartate transaminase; CTACE, conventional transarterial chemoembolization; DEB-TACE, drug-eluting beads transarterial chemoembolization; TACE, transarterial chemoembolization. 
DEB-TACE $(\mathrm{N}=42)$

\begin{tabular}{|c|c|c|c|}
\hline & & Major complications & \\
\hline & 3 (7.1\%) "IIIIIIIIII, & Liver abscess & $1(5.3 \%)$ \\
\hline & $1(2.4 \%) \mathrm{W/N}$ & Massive Pleural effusion & $2(10.5 \%)$ \\
\hline & $1(2.4 \%) \% / /$, & Acute cholangitis & $1(5.3 \%)$ \\
\hline & $1(2.4 \%) \mathrm{W} / /$. & Acute pancreatitis & 0 \\
\hline & $1(2.4 \%) \mathrm{W} / / /$ & Spinal infarction & 0 \\
\hline & & Minor complications & \\
\hline $15(35.7 \%)$ & & Basal atelectasis & $5(26.3 \%)$ \\
\hline $11(26.2 \%)$ & & Pleural effusion & $5(26.3 \%)$ \\
\hline & $6(14.3 \%) \geqslant / / /$ & Shoulder pain & $2(10.5 \%)$ \\
\hline & $1(2.4 \%) \quad W / / /$, & Paroxysmal atrial fibrillation & $1(5.3 \%)$ \\
\hline & $1(2.4 \%) \quad \mathscr{W} /$. & Ecchymosis over chest wall & $1(5.3 \%)$ \\
\hline & $1(2.4 \%) \quad \mathbb{H}_{1}$ & Splenic infarction & 0 \\
\hline
\end{tabular}

Figure 6 Major and minor complications occurred within three months after TACE. Pulmonary complications included massive pleural effusion (which need thoracentesis and is categorized as major complication), basal atelectasis and pleural effusion. DEB-TACE group had seven episodes (I6.6\%) of major complications and cTACE group had four episodes (21.1\%) respectively. Twenty-four patients in DEB-TACE group and 10 patients in cTACE group had minor complications (the development of more than two minor complications was found in six patients in DEB-TACE group and three patients in cTACE group).
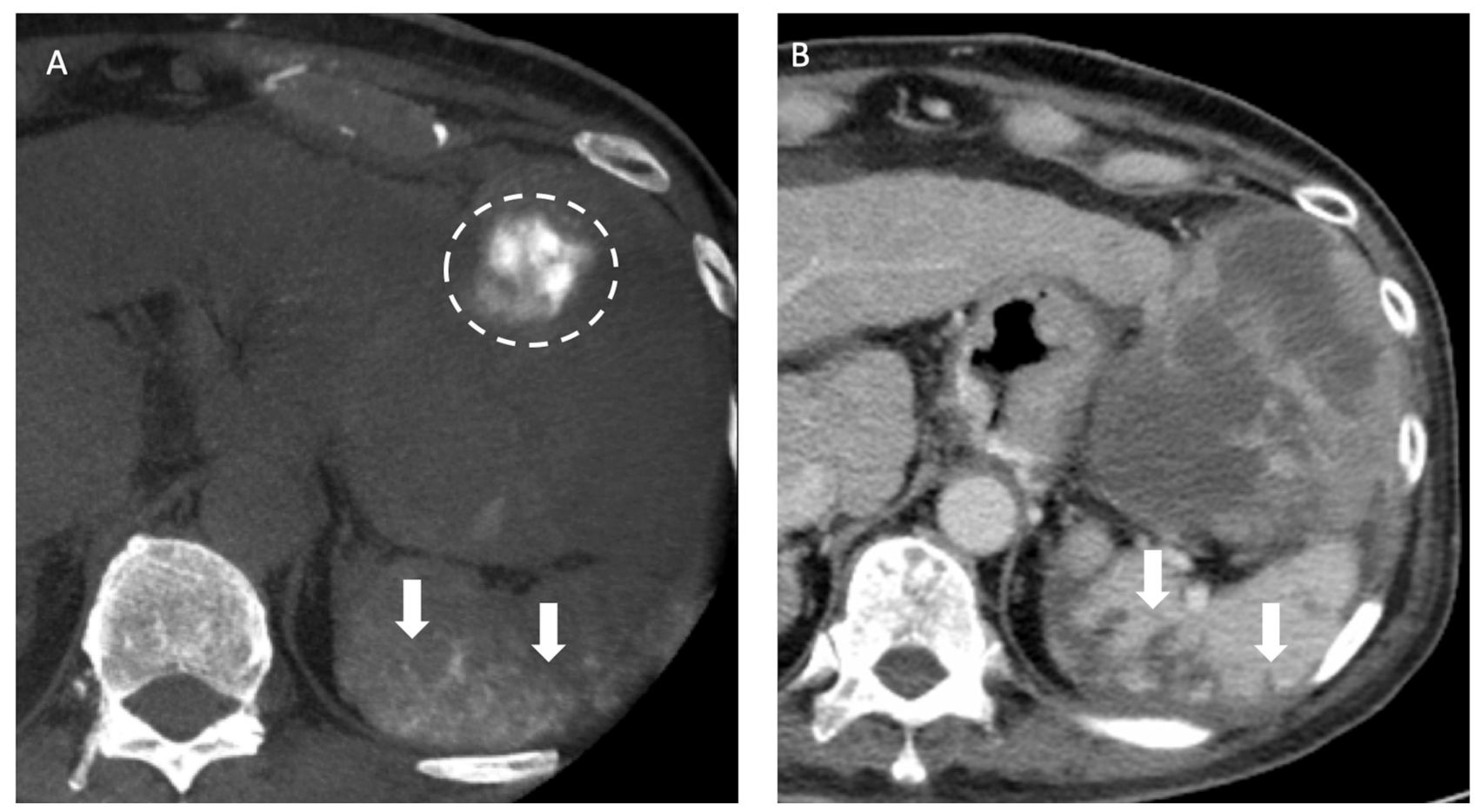

Figure 7 Recurrent HCCs in a 70-year old man with HBV cirrhosis of liver and HCC in the both lobes of the liver received TACE before. (A) After the chemoembolization of splenic artery with drug-eluting beads, the nonenhanced CBCT after TACE showed contrast retention in the spleen (arrows), indicative of nontarget embolization. Also note contrast retention in the HCC located in the left lateral segment of liver (dotted line). (B) The follow-up CT one month after TACE showed wedge-shaped poorenhancing area (arrows) in the spleen on portal venous phase, compatible with splenic infarction caused by nontarget embolization during TACE. 
embolize the tumor-supplying arteries, not only from EHC arteries, but also from hepatic arteries in the same TACE session.

In conclusion, our study showed that DEB-TACE has potential therapeutic efficacy in the treatment of EHC blood supplies of unresectable HCC with comparable safety compared with cTACE. Further prospective randomized studies with larger numbers of patients and baseline stratification according to tumor characteristics are needed to compare the two types of TACE in the treatment of EHC blood supplies.

\section{Acknowledgments}

This study was supported by study project of Tri-Service General Hospital (TSGH-C108-055) and Ministry of Science of Technology (MOST 109-2314-B-016-012). The authors thank the Cancer Registry Group of TriService General Hospital for the clinical data support.

\section{Disclosure}

The authors report no conflicts of interest in this work.

\section{References}

1. European Association For The Study of The Liver. EASL clinical practice guidelines: management of hepatocellular carcinoma. J Hepatol. 2018;69(1):182-236. doi:10.1016/j.jhep.2018.03.019

2. Varghese J, Kedarisetty C, Venkataraman J, et al. Combination of TACE and sorafenib improves outcomes in BCLC stages B/C of hepatocellular carcinoma: a single centre experience. Ann Hepatol. 2017;16(2):247-254. doi:10.5604/16652681.1231585

3. Pan T, Li XS, Xie QK, et al. Safety and efficacy of transarterial chemoembolization plus sorafenib for hepatocellular carcinoma with portal venous tumour thrombus. Clin Radiol. 2014;69(12):e553-561. doi:10.1016/j.crad.2014.09.007

4. Konno T, Maeda H, Iwai K, et al. Effect of arterial administration of high-molecular-weight anticancer agent SMANCS with lipid lymphographic agent on hepatoma: a preliminary report. Eur J Cancer Clin Oncol. 1983;19(8):1053-1065. doi:10.1016/0277-5379(83)90028-7

5. Nakamura H, Hashimoto T, Oi H, Sawada S. Transcatheter oily chemoembolization of hepatocellular carcinoma. Radiology. 1989;170(3 Pt 1):783-786. doi:10.1148/radiology.170.3.2536946

6. Brown DB, Gould JE, Gervais DA, et al. Transcatheter therapy for hepatic malignancy: standardization of terminology and reporting criteria. J Vasc Interv Radiol. 2009;20(7 Suppl):S425-434. doi:10.1016/j.jvir.2009.04.021

7. Varela M, Real MI, Burrel M, et al. Chemoembolization of hepatocellular carcinoma with drug eluting beads: efficacy and doxorubicin pharmacokinetics. J Hepatol. 2007;46(3):474-481.

8. Sottani C, Poggi G, Quaretti P, et al. Serum pharmacokinetics in patients treated with transarterial chemoembolization (TACE) using two types of epirubicin-loaded microspheres. Anticancer Res. 2012;32 (5):1769-1774.

9. Jiaqi Y, Hori S, Minamitani K, et al. [A new embolic material: super absorbent polymer (SAP) microsphere and its embolic effects]. Nihon Igaku Hoshasen Gakkai Zasshi. 1996;56(1):19-24.
10. Nouri YM, Kim JH, Yoon H-K, Ko H-K, Shin JH, Gwon DI. Update on transarterial chemoembolization with drug-eluting microspheres for hepatocellular carcinoma. Korean J Radiol. 2019;20(1):34-49. doi: $10.3348 / \mathrm{kjr} .2018 .0088$

11. Moustafa AS, Abdel Aal AK, Ertel N, Saad N, DuBay D, Saddekni S. Chemoembolization of hepatocellular carcinoma with extrahepatic collateral blood supply: anatomic and technical considerations. Radiographics. 2017;37(3):963-977. doi:10.1148/ rg.2017160122

12. Watanabe Y, Tokue H, Taketomi-Takahashi A, Tsushima Y. Imaging findings and complications of transcatheter interventional treatments via the inferior phrenic arteries in patients with hepatocellular carcinoma. Eur J Radiol Open. 2018;5:171-176. doi:10.1016/j. ejro.2018.08.010

13. Nhu QM, Knowles H, Pockros PJ, Frenette CT. Pulmonary complications of transcatheter arterial chemoembolization for hepatocellular carcinoma. World J Respirol. 2016;6(3):69-75. doi:10.5320/wjr.v6. i3.69

14. Chung JW, Park JH, Han JK, Choi BI, Kim TK, Han MC. Transcatheter oily chemoembolization of the inferior phrenic artery in hepatocellular carcinoma: the safety and potential therapeutic role. J Vasc Interv Radiol. 1998;9(3):495-500. doi:10.1016/S10510443(98)70306-9

15. Koh S, Maki EJ, Kolbeck KJ, Farsad K. Skin ischemia and ulceration as a complication of inferior phrenic artery embolization for hepatocellular carcinoma. Radiol Case Rep. 2018;13(3):648-651. doi:10.1016/j.radcr.2018.02.032

16. Marrero JA, Kulik LM, Sirlin CB, et al. Diagnosis, staging, and management of hepatocellular carcinoma: 2018 practice guidance by the American association for the study of liver diseases. Hepatology. 2018;68(2):723-750.

17. Kudo M, Izumi N, Ichida T, et al. Report of the 19th follow-up survey of primary liver cancer in Japan. Hepatol Res. 2016;46 (5):372-390. doi:10.1111/hepr.12697

18. Mei Q, Li Y. Transcatheter arterial embolization of hepatic arteriovenous shunts in patients with hepatocellular carcinoma. Semin Intervent Radiol. 2012;29(3):237-240. doi:10.1055/s-0032-1326935

19. Tacher V, Radaelli A, Lin M, Geschwind J-F. How I do it: cone-beam CT during transarterial chemoembolization for liver cancer. Radiology. 2015;274(2):320-334. doi:10.1148/radiol.14131925

20. Jin B, Wang D, Lewandowski RJ, et al. Chemoembolization endpoints: effect on survival among patients with hepatocellular carcinoma. AJR Am J Roentgenol. 2011;196(4):919-928. doi:10.2214/AJR.10.4770

21. Lencioni R, Llovet JM. Modified RECIST (mRECIST) assessment for hepatocellular carcinoma. Semin Liver Dis. 2010;30(1):52-60. doi:10.1055/s-0030-1247132

22. Wang W-D, Zhang L-H, Ni J-Y, et al. Radiofrequency ablation combined with transcatheter arterial chemoembolization therapy versus surgical resection for hepatocellular carcinoma within the milan criteria: a meta-analysis. Korean J Radiol. 2018;19(4):613-622.

23. Song MJ, Chun HJ, Song DS, et al. Comparative study between doxorubicin-eluting beads and conventional transarterial chemoembolization for treatment of hepatocellular carcinoma. $J$ Hepatol. 2012;57(6):1244-1250. doi:10.1016/j.jhep.2012.07.017

24. Lammer J, Malagari K, Vogl T, et al. Prospective randomized study of doxorubicin-eluting-bead embolization in the treatment of hepatocellular carcinoma: results of the PRECISION V study. Cardiovasc Intervent Radiol. 2010;33(1):41-52. doi:10.1007/s00270-009-9711-7

25. Lee YK, Jung KS, Kim DY, et al. Conventional versus drug-eluting beads chemoembolization for hepatocellular carcinoma: emphasis on the impact of tumor size. J Gastroenterol Hepatol. 2017;32 (2):487-496. doi:10.1111/jgh.13501

26. Miyayama SH, Matsui OS. Applying superselective conventional TACE. Endovasc Today. 2017;16:52-56. 
27. Dreher MR, Sharma KV, Woods DL, et al. Radiopaque drug-eluting beads for transcatheter embolotherapy: experimental study of drug penetration and coverage in swine. J Vasc Interv Radiol. 2012;23 (2):257-264.e254. doi:10.1016/j.jvir.2011.10.019

28. Prajapati HJ, Xing M, Spivey JR, et al. Survival, efficacy, and safety of small versus large doxorubicin drug-eluting beads TACE chemoembolization in patients with unresectable HCC. AJR Am J Roentgenol. 2014;203(6):W706-714. doi:10.2214/AJR.13.12308

29. Golfieri R, Giampalma E, Renzulli M, et al. Randomised controlled trial of doxorubicin-eluting beads vs conventional chemoembolisation for hepatocellular carcinoma. $B r J$ Cancer. 2014;111:255. doi:10.1038/bjc.2014.199

30. Lucatelli $\mathrm{P}$, Corona $\mathrm{M}$, Argirò $\mathrm{R}$, et al. Impact of 3D rotational angiography on liver embolization procedures: review of technique and applications. Cardiovasc Intervent Radiol. 2015;38(3):523-535. doi:10.1007/s00270-014-1023-x

31. Lucatelli P, Argirò R, Ginanni Corradini S, et al. Comparison of image quality and diagnostic performance of cone-beam CT during drug-eluting embolic transarterial chemoembolization and multidetector CT in the detection of hepatocellular carcinoma. J Vasc Interv Radiol. 2017;28(7):978-986.

32. Lucatelli P, De Rubeis G, Ginnani Corradini L, et al. Intra-procedural dual phase cone beam computed tomography has a better diagnostic accuracy over pre-procedural MRI and MDCT in detection and characterization of HCC in cirrhotic patients undergoing TACE procedure. Eur J Radiol. 2020;124:108806. doi:10.1016/j. ejrad.2019.108806
33. Lucatelli P, De Rubeis G, Basilico F, et al. Sequential dual-phase cone-beam $\mathrm{CT}$ is able to intra-procedurally predict the one-month treatment outcome of multi-focal $\mathrm{HCC}$, in course of degradable starch microsphere TACE. Radiol Med. 2019;124(12):1212-1219. doi:10.1007/s11547-019-01076-y

34. Lucatelli $\mathrm{P}$, Argirò R, Bascetta $\mathrm{S}$, et al. Single injection dual phase $\mathrm{CBCT}$ technique ameliorates results of trans-arterial chemoembolization for hepatocellular cancer. Transl Gastroenterol Hepatol. 2017;2:83. doi:10.21037/tgh.2017.10.03

35. Kim HC, Chung JW, Park JH, et al. Transcatheter arterial chemoembolization for hepatocellular carcinoma: prospective assessment of the right inferior phrenic artery with C-arm CT. J Vasc Interv Radiol. 2009;20(7):888-895. doi:10.1016/j.jvir.2009.03.036

36. Kim H-C. Role of C-arm cone-beam CT in chemoembolization for hepatocellular carcinoma. Korean J Radiol. 2015;16(1):114-124. doi:10.3348/kjr.2015.16.1.114
Drug Design, Development and Therapy

\section{Publish your work in this journal}

Drug Design, Development and Therapy is an international, peerreviewed open-access journal that spans the spectrum of drug design and development through to clinical applications. Clinical outcomes, patient safety, and programs for the development and effective, safe, and sustained use of medicines are a feature of the journal, which has also

\section{Dovepress}

been accepted for indexing on PubMed Central. The manuscript management system is completely online and includes a very quick and fair peer-review system, which is all easy to use. Visit http://www. dovepress.com/testimonials.php to read real quotes from published authors. 